\title{
The High Price of Success: Costs of Mating Effort in Male Primates
}

\author{
Melissa Emery Thompson • Alexander V. Georgiev
}

Received: 31 May 2014 / Accepted: 4 June 2014 / Published online: 5 August 2014

(C) Springer Science+Business Media New York 2014

\begin{abstract}
While males are generally the low investing sex when it comes to offspring care, males of many species experience intense and persistent mating effort. Mating effort incurs a variety of costs which are expected to have non-negligible effects on fitness, as well as how reproductive tactics are selected and investment in mating activity is moderated over time. This special issue features contributions investigating the costs of male mating effort across primate species. Here, we place these exciting new works in context, addressing the specific types of mating effort expected for male primates and the significance of these costs for our understanding of primate life histories and socioecology.
\end{abstract}

Keywords Reproductive strategies · Glucocorticoids $\cdot$ Energetics $\cdot$ Life history $\cdot$ Malemale competition - Testosterone

\section{Introduction}

A fundamental premise in mammalian socioecology is that females are burdened with disproportionately high costs of reproduction in comparison with males. Female reproductive success is, therefore, predicted to be limited by access to energetic resources while male reproductive success is limited primarily by access to mates (Bateman 1948; Trivers 1972). While this paradigm has tremendous power to predict sex differences in behavior and other aspects of biology, it has skewed how male and female reproductive strategies are examined. Studies of females tend to focus on reproductive costs and how they are managed (e.g., resource competition, seasonality, birth spacing), whereas studies of males tend to focus on quantifying and predicting reproductive benefits. The primate literature, in particular, has overlooked the costs that

M. Emery Thompson $(\bowtie)$

Department of Anthropology, University of New Mexico, MSC01-1040, 500 University Blvd., NE, Albuquerque, NM 87131, USA

e-mail: memery@unm.edu

\section{A. V. Georgiev}

Institute for Mind and Biology, The University of Chicago, 940 East 57th St, Chicago, IL 60637, USA 
males incur in the pursuit of reproductive success. This is a departure from the literature on non-mammalian species, as well as the broader spheres of life history theory, in which reproduction is recognized to carry significant physiological costs (Bell 1980; Roff 1992; Stearns 1992; Zera \& Harshman 2001), and sexual selection theory, in which costs of male displays occupy a central role (Zahavi 1975, 1977; Andersson 1986; Johnstone 1995; Höglund \& Sheldon 1998).

Many primates are highly social and long-lived, meaning that males experience intense and persistent mating effort during their lifetimes. Mating effort can entail direct aggressive competition with other males, indirect forms of competition such as physical, vocal, and behavioral displays, increased vigilance, altered travel and grouping patterns, and persistent or coercive interactions with females (Dixson 2013). These activities can be predicted to drive a variety of costs, including risk of injury, reduction in energetic condition, physiological stress, and the tradeoffs associated with diverting resources toward obtaining status and mating opportunities (Kappeler \& van Schaik 2004). Ultimately, the costs needed to reproduce successfully can fundamentally constrain the fitness potential of males and may be, in some cases, proportionately higher or more prohibitive than the costs experienced by females (Key \& Ross 1999). However, basic data on the costs of reproduction in male primates are scarce.

To remedy this shortcoming, we invited a diverse group of scholars to consider this problem in a symposium at the $82^{\text {nd }}$ Annual Meeting of the American Association of Physical Anthropologists in Knoxville, TN on April 12, 2013 (Georgiev \& Emery Thompson 2013). The symposium, co-sponsored by the Human Biology Association, featured 13 speakers bringing multi-disciplinary approaches to the costs of reproduction in a range of primate species, including humans. This special issue comprises nine papers from that symposium, with two additional contributions. These include studies providing detailed empirical evidence for specific costs of mating effort, evaluations of hormonal mechanisms regulating male life history tradeoffs, and evidence-based comparative models for how costs can be expected to vary across different primate mating systems and taxonomic groups. We present here an overview of the ways in which mating effort may be costly for primate males, contextualizing the contributed papers with one another and with the existing mammalian literature. This culminates in a discussion of the theoretical and empirical challenges raised by this new work, providing prospects for future research.

\section{What Are the Costs of Mating Effort?}

\section{Physical Injury}

A primary cost of male competition is the risk of injury. Among male primates, this risk is exacerbated by selection for large body size and elongated canine teeth (Plavcan \& van Schaik 1992; Mitani et al. 1996). Not surprisingly, the species with the most dimorphic canine teeth experience high rates of wounding. For example, gelada baboons (Theropithecus gelada) receive severe injuries in about one-quarter of all fights, chiefly in the context of harem defense (Dunbar 1984). In Tibetan macaques (Macaca thibetana), 71 wounds and 3 deaths were recorded among 36 study males during a single 3-month mating season (Zhao 1994). A high incidence of wounding has 
been reported in mandrills (Mandrillus sphinx: Setchell \& Wickings, 2005), gorillas (Gorilla beringei: Robbins, 1996), baboons (Papio cynocephalus: Drews 1996; Papio anubis: MacCormick et al. 2012), and various other species (Arlet, Carey, \& Molleman 2009; Smuts 1987). While wounding events are often not observed and thus cannot be directly attributed to male-male competition, most studies report higher rates of wounding during the breeding season, among males relative to females, among lowranking or subadult individuals relative to dominants, and in locations consistent with observed male-male combat (e.g., canine slashes to the face). Among arboreal primates, fights may also lead to accidental falls from trees (Arlet et al. 2009). While primates are rarely directly killed in male-male combat (Newton-Fisher \& Emery Thompson 2012), wounds may persist for several weeks (Archie et al. 2012). Aside from the risk of infection, wound healing can involve compromised foraging or traveling efficiency, withdrawal from social groups, and loss of status (Drews 1996). In this volume, Stone (2014) reports that male squirrel monkeys experience an increased prevalence of wounds, including broken bones and severe gashes, associated with concentrated male-male agonism in the mating season.

Along with the risk of injury or death from intraspecific aggression, mating investment can increase the probability of predation by reducing vigilance or by altering normal grouping patterns (Magnhagen 1991). While systematic evidence for this in primates is lacking, the risk of predation figures heavily in determining primate group sizes (van Schaik 1983; Janson \& Goldsmith 1995) and may be assumed to pose an increased risk to individuals whose attention is focused on mating.

\section{Physiological Stress}

Primates exhibit elevations in glucocorticoids (chiefly, cortisol) in response to a wide range of environmental and social stressors, enabling the "fight-or-flight" response, a critical adaptation that allows an animal to produce a quick and coordinated response to a potential threat (Sapolsky 1992, 1998). While this response promotes survival, it can have damaging collateral consequences. The stress response diverts energy away from the body's regular somatic maintenance processes, such as immune function and cellular repair, towards the immediate needs for cardiovascular and muscular performance. By straining some systems and reducing investment in others, chronic activation of the stress response can lead to a variety of adverse long-term health impacts, including cardiovascular disease, immune disorders, accelerated aging, and reduced cognitive performance (Sapolsky 1998, 2004, 2005).

Advances in non-invasive methodologies have triggered a profusion of research on stress in wild primates, with many studies asking how social status affects glucocorticoid levels. Social subordination, which often entails resource limitations and increased targeting for aggression, was assumed to be the more stressful circumstance, and in many cases it is. However, this relationship is inconsistent across species, and contradictory results are reported within the same species or even within the same group over time (Creel 2001; Abbott et al. 2003; Honess \& Marin 2006). The behavioral correlates of dominance rank, and their variance with context, are probably more salient than rank itself. Of particular interest are studies that find that during periods of hierarchy instability the glucocorticoid levels of dominant males, who experience frequent challenges and invest more heavily in aggression, meet or exceed those of subordinates (Sapolsky 1983; Bergman et al. 2005; 
Higham et al. 2013; Setchell et al. 2010). This suggests that investment into attaining and maintaining dominance rank, often an important determinant of priority of access to females, entails significant physiological costs. It also hints that the behaviors involved in mating competition in many primates engender stress.

Other studies, including some in this volume, have assessed more directly the influence of mating investments on glucocorticoid levels. For example, in seasonallybreeding redfronted lemurs (Eulemur fulvus rufus: Ostner et al. 2008b), tufted capuchins (Cebus apella nigritus: Lynch et al. 2002), and Assamese macaques (Macaca assamensis: Ostner et al. 2008a), glucocorticoid levels of males were higher during the mating season than at other times. In this volume, Schoof et al. (2014) used hormonal information to identify the days on which white-faced capuchin (Cebus capucinus) females were near ovulation, finding that male glucocorticoid levels were significantly elevated when such females were present.

A key feature of the endocrine stress response is that it is highly generalized across contexts. Importantly, the fundamental effect of glucocorticoids is to increase the circulating levels of glucose should energy be needed to mount a behavioral response to a challenge (Sapolsky 1992; Genuth 1993). Thus, in addition to the potential psychosocial stress associated with elevated aggression, mating effort can also increase glucocorticoids by creating energetic stress (Bercovitch \& Ziegler 2002; Muller \& Wrangham 2004). This may explain why males in species such as muriquis (Brachyteles arachnoides) experience elevated cortisol during mating periods despite low levels of overt male contest (Strier et al. 1999). Accordingly, male golden lion tamarins (Leontopithecus rosalia), which engage in energeticallytaxing paternal effort, have moderately higher levels of glucocorticoids during the birth season than during mating periods (Bales et al. 2005). In this volume, Schülke et al. (2014) report that glucocorticoid levels did not increase with mating effort in wild Assamese macaques, and mate-guarding did not impose measurable energetic costs. Finally, while Girard-Buttoz et al. (2014a) did find higher glucocorticoids in association with mating effort in long-tailed macaques (Macaca fascicularis), the effect was greater when males were guarding low-ranking (less desirable) females, when males fed less, than when guarding high-ranking females, when males were more vigilant and aggressive. Further research on mating effort and stress should follow these examples in attempting to disentangle energetic from psychosocial stressors. This is particularly important when mating seasons coincide with periods of reduced food availability.

\section{Energetic Stress}

Mating effort can bring about energetic stress in a number of ways. First, the intensity of male mating competition is a key predictor of body size dimorphism in primates (Mitani et al. 1996; Plavcan \& van Schaik 1997). In highly dimorphic species (when males are at least $\sim 60 \%$ larger), the extra costs of male body mass can actually raise the daily energy expenditure beyond that experienced by lactating females (Key \& Ross 1999). This is before any consideration of energetically-costly behaviors associated with mating effort. Studies of other mammals suggest these costs may also be quite substantial. For example, in the minimally-dimorphic North American red squirrel (Tamiasciurus hudsonicus), total energy expenditure (assessed with doubly-labelled water) of males approximated that of lactating 
females; expenditure was predicted by mate search effort, which was in turn constrained by low resource availability (Lane et al. 2010).

Several primate studies note that male mating effort reduces foraging effort, particularly when males are guarding or following females (Papio cynocephalus: Alberts et al. 1996; Rasmussen, 1985; Macaca fuscata: Matsubara, 2003; Macaca fascicularis: Girard-Buttoz et al. 2014b; Macaca mulatta: Higham et al. 2011). This need not indicate a reduction in caloric intake if males are able to compensate by eating foods of higher nutritional quality (c.f., lactating females: Dufour \& Sauther 2002), nor does it necessarily lead to loss of condition (Girard-Buttoz et al. 2014b), though this is a likely consequence. As reported by Higham and Maestripieri (2014 this volume, see also Higham et al. 2011), high-ranking male rhesus macaques spent more time consorting, and less time feeding, during the breeding season than did low-ranking males, and suffered energetic consequences; while dominant males began the breeding season with relatively high C-peptide of insulin levels (indicating positive energy balance: Girard-Buttoz et al. 2011), they ended with significantly lower levels than subordinates. An analogous process may occur in squirrel monkeys wherein seasonal fattening of males predicts increased time in association with breeding females and reductions in feeding time (Stone 2014 this volume). Seasonal weight gains in some seasonally-breeding primate males may serve to buffer the high costs associated with mating effort, or may be a way to avoid paying the high metabolic costs of maintaining a robust physique year-round.

Primate males may also increase their energetic expenditure during mating effort. For example, if mates are dispersed, as in gray mouse lemurs (Microcebus murinus: Eberle \& Kappeler 2004) or orangutans (Pongo pygmaeus: Knott \& Emery Thompson 2013), male search effort can be costly and dependent on maintaining adequate condition. Male aggression and physical display can also be energetically costly (Muller \& Wrangham 2004). Direct data on the energetic costs of aggression are rare for primates, but are elegantly shown in experimental studies of lizards (Sceloporus jarrovi: Marler \& Moore 1988) and invertebrates (Acheta domesticus: Hack 1997).

For some species, energy may be every bit the constraint on male reproductive success that it is for females. Across mammals, most evidence for the energetic effects of mating arise from seasonally-breeding species, suggesting that costs might be most apparent when males experience concentrated periods of reproductive effort (e.g., Cervus elaphus: Clutton-Brock et al. 1982; Mirounga leonina: Galimberti et al. 2007; Macaca mulatta: Higham et al. 2011). However, this volume contains one study of a seasonally-breeding species (M. assamensis) in which males actually fed more when mate-guarding, and in which mating effort was unrelated to body condition (Schülke et al. 2014). By contrast, in aseasonally-breeding chimpanzees (Pan troglodytes), mating opportunities, and specifically aggression and copulation rates, predicted reductions in feeding time (Georgiev et al. 2014 this volume). In contrast to seasonal breeders, species like chimpanzees appear to experience more persistent costs over time with fewer opportunities to recover their condition.

\section{Immune Function and Somatic Health}

Reproductive effort can affect the immune system and somatic maintenance in at least two ways. First, investments in behavioral and morphological aspects of reproductive effort divert resources away from the immune system, cellular repair, and similar 
survival-enhancing processes (Lochmiller \& Deerenberg 2000; McDade 2003; Schmid-Hempel 2003; Harshman \& Zera 2007). Second, the steroid testosterone, which promotes reproductive effort, can directly inhibit components of the immune system (Folstad \& Karter 1992; Klein 2000; Schmid-Hempel 2003), a phenomenon that has received considerable attention.

Most confirmatory evidence for immune suppression by testosterone derives either from in vitro studies or from experimental manipulations of testosterone. Data on naturally-occurring variation in vivo are minimal, particularly for primates, and provide mixed evidence that testosterone (or reproductive effort writ large) impairs immunity (Muehlenbein \& Bribiescas 2005; Harshman \& Zera 2007). Many studies, such as the paper in this volume by Gettler et al. (2014), who examined intraindividual variation in Filipino men, find a positive correlation between testosterone and measures of immune function. Such positive associations may, in fact, reaffirm the costliness of testosterone, if it is the case that only high-quality males can afford its costs (Folstad \& Karter 1992). In this volume, Prall and Muehlenbein (2014) provide an updated review of the literature on testosterone and immunity in primates, pointing out methodological issues, such as the challenge of accurately characterizing immune health (see also Roberts, Buchanan, \& Evans 2004; Muehlenbein \& Bribiescas 2005; Harshman \& Zera 2007). They highlight the potential role of individual energetic condition as a mediator of trade-offs, implicate the likely potentiating effects of other hormones such as glucocorticoids, and note a significant problem with causality in that immunological challenges can themselves suppress testosterone. Several authors propose that, while testosterone can play a mediating role, sex differences in immunocompetence are the result of long-term selection on male life histories to invest in reproduction at the expense of maintenance (Klein 2000; Zuk \& Stoehr 2002; Nunn et al. 2009).

In addition to its potential effects on the immune system, reproductive effort can increase an organism's vulnerability to other kinds of somatic stress, including both external sources (e.g., toxins, environmental stress) and internal sources (e.g., cellular damage) (Harshman \& Zera 2007). A growing literature, primarily from birds and insects, focuses on oxidative stress as a potential cost of reproduction. Oxidative stress is the result of an imbalance between the damage produced by reactive oxygen species and the body's ability to repair or prevent that damage. Accumulated oxidative stress appears to be integrally involved in the aging process (Finkel \& Holbrook 2000; Sohal $\&$ Weindruch 1996). Reproductive effort could increase oxidative stress via an increased rate of damage, decreased antioxidant activity, decreased investment in repair, or a combination of these (Monaghan et al. 2009). Studies of zebra finches, for example, associate male reproductive effort with a reduction in antioxidant activity (Alonso-Alvarez et al. 2004, 2006). More broadly, mating effort that involves physical exertion is expected to increase oxidative damage (Powers \& Jackson 2008), though other evidence suggests that the caloric restriction experienced by many breeding males could reduce long-term oxidative stress (Sohal \& Weindruch 1996). The literature on oxidative stress parallels that on immune function in that : (a) testosterone and/or glucocorticoids are suggested to mediate oxidative stress during reproductive efforts (Alonso-Alvarez et al. 2007; Metcalfe \& Alonso-Alvarez 2010; Costantini et al. 2011), (b) most studies employ only limited measures of oxidative stress, (c) few naturalistic studies have been conducted, (d) the long-term health effects of oxidative stress 
accrued during breeding are unknown (Costantini 2008; Monaghan et al. 2009). Studies evaluating oxidative stress as a cost of mating effort in free-living primates have not yet been conducted.

\section{Infectious Disease Exposure}

Just as mating effort may increase susceptibility to pathogens, it can also increase exposure to pathogens. Mating behavior can most obviously increase transmission of sexually-transmitted diseases (STDs), but may also influence ordinary infectious disease transmission if social contacts are increased during breeding or if alterations in ranging patterns affect exposure to fecal parasites (Moller et al. 1993; Altizer et al. 2003; Nunn et al. 2011; Rushmore et al. 2013). In this volume, Nunn et al. (2014) refine predictive models for STD prevalence in primates, integrating the interspecific variation in the influences that age and rank have on relative male mating success (see also: Thrall et al. 2000; Nunn \& Altizer 2004).

\section{Social Costs}

In many primates, males use alliances with other males to improve rank or mating access, to defend access to mates or resources, or to engage in other cooperative efforts (e.g., vigilance: Rose \& Fedigan 1995; hunting: Watts \& Mitani 2002; intergroup aggression: Wilson \& Wrangham 2003). Primate males often must balance the benefits of these relationships against individual success in intragroup mating competition. Thus, a cost of mating effort in multi-male groups can be strain on affiliative or cooperative relationships within groups, threatening these relationships or necessitating increased investment in relationship maintenance (de Waal 2000; Aureli et al. 2002; Muller \& Mitani 2005). Such costs can be difficult to evaluate and to interpret, particularly when alliances are used to facilitate mating access for one or both partners (Chapais 1995; Watts 1998; Duffy et al. 2007). For example, in gelada baboons (Theropithecus gelada) males with subordinate male followers lose a share of matings to these males but benefit by maintaining a longer tenure (SnyderMackler et al. 2012).

\section{Tradeoff with Parenting Effort}

Papers in this issue focus on the mating component of male reproductive effort. However, many primates invest in some form of parenting effort, such as feeding, carrying, play, or protection (Wright 1990; Fernandez-Duque et al. 2009). Paternal care can promote the health and survival of offspring, but, like mating effort, consumes time, energy, and attention. While at least some forms of paternal effort can double as mating effort (van Schaik \& Paul 1996), male primates generally face tradeoffs between seeking new mating opportunities and investing in current offspring (Smuts \& Gubernick 1992). Testosterone appears to mediate this tradeoff, increasing during times of high mating investment and decreasing during offspring care (Wingfield et al. 1990; Muller \& Emery Thompson 2012; Gettler et al. 2014). 


\section{Costs of Insemination}

Sperm may also not be as cheap as widely assumed, though this is difficult to assess because sperm production is often concurrent with other kinds of effort. This has clearly been assessed in a non-primate species, the adder (Vipera berus), for which reproduction is divided into two delimited phases: an initial period of spermatogenesis and immobility followed by a phase of active mate search and reproductive competition. Male adders lost as much weight during sperm production as they did in the more active components of mating effort (Olsson et al. 1997). Aside from spermatogenesis, ejaculate production may also carry energetic costs. Using caloric analysis of ejaculates, Thomsen et al. (2006) estimated that, depending on male size and frequency of copulation, male Japanese macaques (Macaca fuscata) spend between $0.8 \%$ and $6 \%$ of their basal metabolic rate producing ejaculate during the breeding season. Sperm production is also rate-limited, meaning that effort used to inseminate one female may constrain the ability to inseminate others (Small 1988; Wedell et al. 2002).

\section{Costly Signaling}

Aside from direct investments in mating effort, males of many species invest in behavioral displays, vocalizations, and ornaments that can aid in signaling competitive ability, physical condition, or genetic quality to both male competitors and potential female mates (Zahavi 1977; Folstad \& Karter 1992; Andersson 1994). These signals function effectively only if they are costly, thus the investment required to develop and maintain such traits are assumed to limit their expression to those males who can afford to produce them. While condition-dependence suggests that investment in mating displays should not be disproportionately costly to any male, this does not negate the importance of these expenditures in male life history tradeoffs. Furthermore, whereas the affordability of incremental costs, such as energetic investment, might reasonably be calibrated based on recent condition, risks - such as injury, predation, or death from opportunistic infection - cannot be as easily forecast.

Ornamental signals of mate quality are less pronounced in primates than in some other taxa, such as birds, perhaps because female choice is so often undermined by malemale competition or sexual coercion (Clutton-Brock \& McAuliffe 2009). Similarly, status badges in primates are less important than in species where individuals lack social knowledge of others (e.g. ungulates). However, signals that reflect the current state of individuals, augmenting past knowledge, are expected to be important (Bergman \& Sheehan 2013). Loud wahoo-calling 'contests' among chacma baboons are a welldocumented example: they are hypothesized to indicate fighting ability ('stamina') as their intensity decreases with age and fatigue (Fischer et al. 2004) and males use them to assess potential rivals (Kitchen et al. 2013). A variety of species exhibit colored ornaments that correlate with social status (e.g., blue scota in vervets (Cercopithecus aethiops), Gerald 2001; red chest patches in gelada baboons: Bergman et al. 2009), female preference (red faces in rhesus macaques: Dubuc et al. 2014; Higham \& Maestripieri 2014 this volume), or both (mandrills: Setchell \& Dixson 2001; Setchell \& Wickings 2005; Setchell 2005). Red skin is linked to androgen levels in at least some 
species, waxing and waning with mating effort and/or rank instability (Setchell et al. 2008; Dixson 2013). While often integrated with red, blue coloration does not follow the same patterns (Dixson 2013; Setchell \& Dixson 2001). Darker blue scrotal coloration was instead reported to reflect serotonergic activity in vervets, potentially marking bearers as targets for aggression (Gerald \& McGuire 2007; Gerald 2001). In most cases it is not yet known how condition-dependent such traits are, what their proximate costs are, or what particular aspects of male condition they reveal.

\section{Multidimensional Costs}

It is important to recognize that the specific costs of mating effort, as outlined above, are often not independent of one another. For example, when mating effort induces a glucocorticoid response, this can also affect the immune system, increasing susceptibility to disease and impairing the wound healing process (Sapolsky 2005; Christian et al. 2006; Segerstrom 2007). This may explain why, over a 27 -year observation period at Amboseli, low-ranking male baboons were ill more often and suffered slower recovery time from injuries than high-ranking males (Archie et al. 2012). In long-tailed macaques, low social status predicted susceptibility to respiratory infection following experimental exposure (Cohen et al. 1997). Similarly, any reductions in energy budget could lead to multiple, diverse effects on somatic health.

\section{Exciting and Unresolved Questions}

\section{How Do the Costs of Mating Effort Impact Male Fitness?}

While males clearly suffer a variety of short-term costs associated with mating effort, a critical question remains whether these costs, particularly when accrued over time, are significant enough to affect long-term survival or fitness. Long-term consequences are difficult to measure directly, but are supported by comparative analyses. Whereas males and females have similar mortality schedules in monogamously-breeding species, males live much shorter lives than females in polygynous species, where male competition for mates is more intense (Allman et al. 1998; Bronikowski et al. 2011). This may be a simultaneous consequence of the accumulated costs of reproduction and weaker selection on longevity, owing in part to the greater potential payoffs for reproductive effort and greater limitations on breeding tenure in males versus females (Clutton-Brock \& Isvaran 2007). However, the timing of mortality events in primates is telling and reveals a proximate role for mating effort in male mortality. In rhesus macaques, females die at higher rates during the birth season, when their costs of reproduction are highest, whereas males die at higher rates during the mating season (Hoffman et al. 2008). A similar clustering of male deaths during the mating season is observed in gray mouse lemurs (Kraus et al. 2008).

The costs of male mating effort can also affect fitness by constraining reproductive lifespan. Across mammals, breeding tenure decreases as the degree of polygyny increases (Lukas \& Clutton-Brock 2014). Whereas low female numbers and low birth rates generally signal greater intensity of male competition (Mitani et al. 1996), more frequent mating opportunities and a higher number of females predict short tenure 
length in cross-species comparisons (Lukas \& Clutton-Brock 2014). This suggests that the frequency, rather than the intensity of mating effort, may limit male reproductive lifespan. In similar fashion, Higham and Maestripieri (2014 this volume; Higham et al. 2011) propose that male fitness in rhesus macaques is determined by the ability to endure repeated mating competition over time (c.f. Andersson 1994).

\section{How Do Costs of Mating Effort Influence Male Mating Tactics?}

Male mating tactics vary in both costs and benefits, covarying with individual features such as competitive ability, energetic condition, and age, and with contextual factors, such as the number of competitors and of sexually-available females, and the availability of food (Dominey 1984). A high payoff strategy may entail costs that are prohibitive for some males. Additionally, the efficacy of many tactics is rankdependent, meaning that males must invest in status competition over a long period of time to succeed. Thus, primates frequently adopt alternative mating tactics that offer a low-cost possibility of siring infants (Setchell 2008; Taborsky et al. 2008; van Schaik et al. 2004). Examples include the use of sneaky copulations (e.g., Cebus apella nigritus: Alfaro 2005) and consortships (e.g., Pan troglodytes: Wroblewski et al. 2009) by subordinates in mating systems in which competition is high and alpha males secure the majority of matings. In an extreme example, many orangutan males exhibit prolonged developmental arrest, which may be a strategy to delay the high costs associated with the large-bodied, flanged phenotype that females prefer (Knott et al. 2010; Knott \& Emery Thompson 2013); while retaining a smaller stature, these males avoid the high costs of direct competition with flanged males and can afford to range more widely in search of females. Variation in male mating tactics across species might also be predicted to correspond with costs of mating effort. For example, male hamadryas baboons (Swedell \& Schreier 2009) and chimpanzees (Muller et al. 2011) use conditioning aggression towards females to increase the effectiveness of mateguarding. By directing aggression towards smaller females and altering their behavior, males minimize the costs of riskier conflicts with competing males. Female choice, when it is not predicated on male dominance, can also alter the costs and benefits of specific types of mating effort (Qvarnström \& Forsgren 1998; Soltis et al. 1997). We suggest that a more comprehensive understanding of primate mating behavior may be gained by closer attention to the costs, and not just the benefits, associated with pursuit of different male mating tactics. A particularly promising opportunity for future long-term research is an assessment of how the costs of mating effort interact with individual condition to predict the adoption of different tactics by an individual male over his lifetime.

Evidence for the costs of male mating effort in primates leads to the prediction that males will modulate effort according not only to their own condition but to the quality of mating opportunities available. Thus, just as the costs of producing infants drive mate selectivity by females (Small 1992), the costs of competition and mate guarding should drive a certain degree of selectivity by males. Males may be expected to invest more intensively in mates that have the highest probability of conceiving and raising offspring successfully. Thus, the bulk of available evidence for male choice in primates indicates preferences for high-ranking females, who have preferential access to food resources, and for parous females, who have higher offspring survival rates (Anderson 1986; Keddy-Hector 1992; Muller et al. 2006; Setchell \& Wickings 2006; Georgiev et al. 2014 this volume; Girard-Buttoz et al. 2014a). 
Recent studies indicate that males in at least some species invest according to the probability that a female will conceive at that time (Saguinus oedipus: Ziegler et al. 1993; Macaca fascicularis: Engelhardt et al. 2004; Pan troglodytes: Emery Thompson \& Wrangham 2008; Cebus capucinus: Schoof et al. 2014 this volume).

How Do Costs of Mating Effort Contribute to Variance in Male Reproductive Success?

To the extent that costs of mating effort affect the affordability of different mating tactics, these costs can contribute to variance in male reproductive success. Costs therefore figure prominently in evaluating evolutionary models for reproductive skew, and by extension affect the genetic structure of primate groups. 'Concession' models posit that dominant males cede a proportion of matings to lower-ranking males as an incentive to keep them in the group or to prevent them from mounting status challenges (Vehrencamp 1983; Keller \& Reeve 1994; Reeve \& Shen 2013). Central to these models is the assumption that alpha males would otherwise have the ability to completely control access to mates, and this assumption is unlikely to be met in most primates (Clutton-Brock 1998). Alternatively, 'tug-of-war' models posit that, at least under some circumstances, alpha males are simply unable to monopolize all mating opportunities (Reeve et al. 1998). One key reason that males may lose a share of matings is that they are unable to afford the costs needed to successfully guard all receptive females. While variants on the 'tug-of-war' model have some power to predict variation in reproductive skew in primates (Kutsukake \& Nunn 2006), the assumptions of these models have also been questioned (Port \& Kappeler 2010). In this volume, Port and Cant (2014) question the traditional model specifications which assume that the costs invested in individual mating effort are experienced as a loss of group productivity. They propose a new dynamic tug-of-war model that operationalizes the costs of mating effort in terms of their potential impacts on male survival and considers how these costs covary with the overlap in female receptive periods. Their theoretical work highlights the need for greater detail on the specific costs of reproduction across a range of species in order to test their predictions. Data on strepsirrhines and New World monkeys are particularly needed.

\section{Conclusion}

In sum, male mating effort in primates entails significant costs experienced across a number of dimensions and time-scales. The costs of mating effort are often overlooked due to compensating reproductive advantages and the assumption that costs are proportional to individual ability to pay. However, recognition of these costs has important ramifications for understanding the dynamics of primate social groups, including the degree of reproductive skew, the variety of reproductive tactics employed by males, the influence of male mate choice, and the stability of group leadership. Preparing for and bearing the costs of mating can be expected to exert critical influences on male life history in primates. Because most primates live in stable social groups and have slow life histories, males experience persistent competition for status, repeated and intense periods of mating investment, and changing opportunities as ecological and social parameters shift. Thus, successfully managing mating expenditures over the long-term is integral to male fitness. The reproductive challenges faced by male primates differ in both kind and degree from the dominant literatures on 
sexual selection in birds and insects, making empirical data all the more essential for revising and refining evolutionary models (Kappeler \& van Schaik 2002, 2004). The papers in this volume collectively represent a major contribution to the knowledge about the evolutionary processes shaping primate males and illustrate novel methodologies, syntheses, and theoretical approaches. We anticipate that this volume will stimulate substantial new work in this area and lay the groundwork for new frontiers in primatology.

Acknowledgments We wish to thank Susan Anton, the American Association of Physical Anthropologists and the Human Biology Association for sponsoring our symposium, Joanna Setchell and James Higham for inviting us to produce this special issue and for their assistance with manuscript review, Dennis Galvez for editorial assistance at Springer, all the contributors to the symposium and the special issue for being willing to share their fantastic work in this venue, Richard Wrangham for serving as discussant at the symposium, Ronan Donovan for his excellent cover image, and all of the reviewers who helped improve contributions to this volume. AVG also thanks Dario Maestripieri and the Institute for Mind and Biology at The University of Chicago for their support during the work on this issue.

\section{References}

Abbott, D. H., Keverne, E. B., Bercovitch, F. B., Shively, C. A., Mendoza, S. P., Saltzman, W., ... Sapolsky, R. M. (2003). Are subordinates always stressed? A comparative analysis of rank differences in cortisol levels among primates. Hormones and Behavior, 43(1), 67-82. doi:10.1016/S0018-506X(02)00037-5

Alberts, S. C., Altmann, J., \& Wilson, M. L. (1996). Mate guarding constrains foraging activity of male baboons. Animal Behaviour, 51, 1269-1277.

Alfaro, J. W. L. (2005). Male mating strategies and reproductive constraints in a group of wild tufted capuchin monkeys (Cebus apella nigritus). American Journal of Primatology, 67(3), 313-328.

Allman, J. M., Rosin, A., Kumar, R., \& Hasenstaub, A. (1998). Parenting and survival in anthropoid primates: caretakers live longer. Proceedings of the National Academy of Science USA, 95, 6866-6869.

Alonso-Alvarez, C., Bertrand, S., Devevey, G., Gaillard, M., Prost, J., Faivre, B., \& Sorci, G. (2004). Increased susceptibility to oxidative stress as a proximate cost of reproduction. Ecology Letters, 7, 363-368.

Alonso-Alvarez, C., Bertrand, S., Devevey, G., Prost, J., Faivre, B., Chastel, O., \& Sorci, G. (2006). An experimental manipulation of life-history trajectories and resistance to oxidative stress. Evolution, 60(9), 1913-1924. doi:10.1111/j.0014-3820.2006.tb00534.x.

Alonso-Alvarez, C., Bertrand, S., Faivre, B., Chastel, O., \& Sorci, G. (2007). Testosterone and oxidative stress: the oxidation handicap hypothesis. Proceedings of the Royal Society of London Series B: Biological Sciences, 274(1611), 819-25. doi:10.1098/rspb.2006.3764.

Altizer, S., Nunn, C. L., Thrall, P. H., Gittleman, J. L., Antonovics, J., Cunningham, A. A., ... Pulliam, J. R. C. (2003). Social organization and parasite risk in mammals: integrating theory and empirical studies. Annual Review of Ecology, Evolution, and Systematics, 34, 517-547. Retrieved from http://www.jstor. org/stable/30033785

Anderson, C. M. (1986). Female age: male preference and reproductive success in primates. International Journal of Primatology, 7(3), 305-325.

Andersson, M. (1986). Evolution of condition-dependent sex ornaments and mating preferences: sexual selection based on viability differences. Evolution, 40, 804-816.

Andersson, M. (1994). Sexual Selection. Princeton: Princeton University Press.

Archie, E. A., Altmann, J., \& Alberts, S. C. (2012). Social status predicts wound healing in wild baboons. Proceedings of the National Academy of Sciences of the United States of America, 109(23), 9017-22. doi: 10.1073/pnas.1206391109.

Arlet, M. E., Carey, J. R., \& Molleman, F. (2009). Species, age and sex differences in type and frequencies of injuries and impairments among four arboreal primate species in Kibale National Park, Uganda. Primates, 50(1), 65-73. doi:10.1007/s10329-008-0119-9.

Aureli, F., Cords, M., \& van Schaik, C. P. (2002). Conflict resolution following aggression in gregarious animals: a predictive framework. Animal Behaviour, 64(3), 325-343. doi:10.1006/anbe.2002.3071.

Bales, K. L., French, J. A., Hostetler, C. M., \& Dietz, J. M. (2005). Social and reproductive factors affecting cortisol levels in wild female golden lion tamarins (Leontopithecus rosalia). American Journal of Primatology, 67(1), 25-35. doi:10.1002/ajp.20167. 
Bateman, A. J. (1948). Intra-sexual selection in Drosophila. Heredity, 2, 349-368.

Bell, G. (1980). The costs of reproduction and their consequences. American Naturalist, 116, 45-76.

Bercovitch, F. B., \& Ziegler, T. E. (2002). Current topics in primate socioendocrinology. Annual Review of Anthropology, 31, 45-67.

Bergman, T. J., Beehner, J. C., Cheney, D. L., Seyfarth, R. M., \& Whitten, P. L. (2005). Correlates of stress in free-ranging male chacma baboons, Papio hamadryas ursinus. Animal Behaviour, 70(3), 703-713. doi: 10.1016/j.anbehav.2004.12.017.

Bergman, T. J., Ho, L., \& Beehner, J. C. (2009). Chest color and social status in male geladas (Theropithecus gelada). International Journal of Primatology, 30(6), 791-806. doi:10.1007/s10764-009-9374-x.

Bergman, T. J., \& Sheehan, M. J. (2013). Social knowledge and signals in primates. American Journal of Primatology, 75(7), 683-94. doi:10.1002/ajp.22103.

Bronikowski, A. M., Altmann, J., Brockman, D. K., Cords, M., Fedigan, L. M., Pusey, A. E., ... Alberts, S. C. (2011). Aging in the natural world: comparative data reveal similar mortality patterns across primates. Science (New York, N.Y.), 331(6022), 1325-8. doi:10.1126/science.1201571

Chapais, B. (1995). Alliances as a means of competition in primates: Evolutionary, developmental, and cognitive aspects. American Journal of Physical Anthropology, 38(S21), 115-136. doi:10.1002/ajpa.1330380607.

Christian, L. M., Graham, J. E., Padgett, D. A., Glaser, R., \& Kiecolt-Glaser, J. K. (2006). Stress and wound healing. Neuroimmunomodulation, 13(5-6), 337-46. doi:10.1159/000104862.

Clutton-Brock, T. H. (1998). Reproductive skew, concessions and limited control. Trends in Ecology \& Evolution, 13(7), 288-292. doi:10.1016/S0169-5347(98)01402-5.

Clutton-Brock, T. H., Guinness, F. E., \& Albon, S. D. (1982). Red Deer: Behavior and Ecology of Two Sexes. (G. B. Schaller, Ed.) Wildlife Behavior and Ecology Series. Chicago: University of Chicago Press.

Clutton-Brock, T. H., \& Isvaran, K. (2007). Sex differences in ageing in natural populations of vertebrates. Proceedings of the Royal Society of London Series B-Biological Sciences, 274(1629), 3097-104. doi:10. 1098/rspb.2007.1138.

Clutton-Brock, T. H., \& McAuliffe, K. (2009). Female mate choice in mammals. The Quarterly Review of Biology, 84(1), 3-27. doi:10.1086/596461.

Cohen, S., Line, S., Manuck, S. B., Rabin, B. S., Heise, E. R., \& Kaplan, J. R. (1997). Chronic social stress, social status, and susceptibility to upper respiratory infections in nonhuman primates. Psychosomatic Medicine, 59, 213-221.

Costantini, D. (2008). Oxidative stress in ecology and evolution: lessons from avian studies. Ecology Letters, 11(11), 1238-51. doi:10.1111/j.1461-0248.2008.01246.x.

Costantini, D., Marasco, V., \& Møller, A. P. (2011). A meta-analysis of glucocorticoids as modulators of oxidative stress in vertebrates. Journal of Comparative Physiology. B, Biochemical, Systemic, and Environmental Physiology, 181(4), 447-56. doi:10.1007/s00360-011-0566-2.

Creel, S. (2001). Social dominance and stress hormones, 16(9), 491-497.

De Waal, F. B. M. (2000). Primates - a natural heritage of conflict resolution. Science, 289, 586-590.

Dixson, A. F. (2013). Primate Sexuality: Comparative Studies of the Prosimians, Monkeys, Apes, and Humans. Oxford University Press, Oxford.

Dominey, W. J. (1984). Alternative mating tactics and evolutionarily stable strategies. Integrative and Comparative Biology, 24(2), 385-396. doi:10.1093/icb/24.2.385.

Drews, C. (1996). Contexts and patterns of injuries in free-ranging male baboons (Papio cynocephalus). Behaviour, 133(5), 443-474.

Dubuc, C., Allen, W. L., Maestripieri, D., \& Higham, J. P. (2014). Is male rhesus macaque red color ornamentation attractive to females? Behavioral Ecology and Sociobiology. doi:10.1007/s00265-014-1732-9.

Duffy, K. G., Wrangham, R. W., \& Silk, J. B. (2007). Male chimpanzees exchange political support for mating opportunities. Current Biology, 17, 586-587.

Dufour, D. L., \& Sauther, M. L. (2002). Comparative and evolutionary dimensions of the energetics of human pregnancy and lactation. American Journal of Human Biology, 14(5), 584-602. doi:10. 1002/ajhb.10071.

Dunbar, R. I. M. (1984). Reproductive Decisions: An Economic Analysis of Gelada Baboon Social Strategies (p. 265 pp). Princeton, NJ: Princeton University Press.

Eberle, M., \& Kappeler, P. M. (2004). Sex in the dark: determinants and consequences of mixed male mating tactics in Microcebus murinus, a small solitary nocturnal primate. Behavioral Ecology and Sociobiology, 57(1), 77-90. doi:10.1007/s00265-004-0826-1.

Emery Thompson, M., \& Wrangham, R. W. (2008). Male mating interest varies with female fecundity in Pan troglodytes of Kanyawara, Kibale National Park. International Journal of Primatology, 29, 885-905. 
Engelhardt, A., Pfeifer, J.-B., Heistermann, M., Niemitz, C., van Hooff, J. A. R. A. M., \& Hodges, J. K. (2004). Assessment of female reproductive status by male longtailed macaques, Macaca fascicularis, under natural conditions. Animal Behaviour, 67(5), 915-924. doi:10.1016/j.anbehav.2003.09.006.

Fernandez-Duque, E., Valeggia, C. R., \& Mendoza, S. P. (2009). The biology of paternal care in human and nonhuman primates. Annual Review of Anthropology, 38, 115-130.

Finkel, T., \& Holbrook, N. J. (2000). Oxidants, oxidative stress and the biology of ageing. Nature, 408, 239247.

Fischer, J., Kitchen, D. M., Seyfarth, R. M., \& Cheney, D. L. (2004). Baboon loud calls advertise male quality: acoustic features and their relation to rank, age, and exhaustion. Behavioral Ecology and Sociobiology, 56(2), 140-148. doi:10.1007/s00265-003-0739-4.

Folstad, I., \& Karter, A. J. (1992). Parasites, bright males, and the immunocompetence handicap. The American Naturalist, 139(3), 603-622. Retrieved from http://www.jstor.org/stable/2462500.

Galimberti, F., Sanvito, S., Braschi, C., \& Boitani, L. (2007). The cost of success: reproductive effort in male southern elephant seals (Mirounga leonina). Behavioral Ecology and Sociobiology, 62(2), 159-171. doi: 10.1007/s00265-007-0450-y.

Genuth, S. M. (1993). The endocrine system. In R. M. Berne \& M. N. Levy (Eds.), Physiology (pp. 8131024). St. Louis: Mosby Year Book.

Georgiev, A. V., \& Emery Thompson, M. (2013). The high price of success: costs of reproductive effort in male primates and humans. American Journal of Physical Anthropology, 150, 25.

Georgiev, A. V, Russell, A. F., Emery Thompson, M., Otali, E., Muller, M. N., \& Wrangham, R. W. (2014). Mating effort constrains foraging in male chimpanzees. International Journal of Primatology, tbd.

Gerald, M. S. (2001). Primate colour predicts social status and aggressive outcome. Animal Behaviour, 61(3), 559-566. doi:10.1006/anbe.2000.1648.

Gerald, M. S., \& McGuire, M. T. (2007). Secondary sexual coloration and CSF 5-HIAA are correlated in vervet monkeys (Cercopithecus aethiops sabaeus). Journal of Medical Primatology, 36(6), 348-54. doi: 10.1111/j.1600-0684.2007.00227.x.

Gettler, L. T., McDade, T. W., Agustin, S. S., Feranil, A. B., \& Kuzawa, C. W. (2014). Testosterone, immune function, and life history transitions in filipino males (Homo sapiens). International Journal of Primatology, tbd. doi:10.1007/s10764-014-9749-5.

Girard-Buttoz, C., Heistermann, M., Rahmi, E., Agil, M., Fauzan, P. A., \& Engelhardt, A. (2014a). Costs of and investment in mate-guarding in wild long-tailed macaques (Macaca fascicularis): Influences of female characteristics and male-female social bonds. International Journal of Primatology. doi:10. 1007/s10764-014-9775-3.

Girard-Buttoz, C., Heistermann, M., Rahmi, E., Marzec, A., Agil, M., Fauzan, P. A., \& Engelhardt, A. (2014b). Mate-guarding constrains feeding activity but not energetic status of wild male long-tailed macaques (Macaca fascicularis). Behavioral Ecology and Sociobiology, 68, 583-595. doi:10.1007/ s00265-013-1673-8.

Girard-Buttoz, C., Higham, J. P., Heistermann, M., Wedegartner, S., Maestripieri, D., \& Engelhardt, A. (2011). Urinary C-peptide measurement as a marker of nutritional status in macaques. Public Library of Science ONE, 6, e18042.

Hack, M. A. (1997). The energetic costs of fighting in the house cricket, Acheta domesticus L. Behavioral Ecology, 8(1), 28-36. doi:10.1093/beheco/8.1.28.

Harshman, L. G., \& Zera, A. J. (2007). The cost of reproduction: the devil in the details. Trends in Ecology \& Evolution, 22(2), 80-6. doi:10.1016/j.tree.2006.10.008.

Higham, J. P., Heistermann, M., \& Maestripieri, D. (2011). The energetics of male-male endurance rivalry in free-ranging rhesus macaques, Macaca mulatta. Animal Behaviour, 81(5), 1001-1007. doi:10.1016/j. anbehav.2011.02.001.

Higham, J. P., Heistermann, M., \& Maestripieri, D. (2013). The endocrinology of male rhesus macaque social and reproductive status: a test of the challenge and social stress hypotheses. Behavioral Ecology and Sociobiology, 67(1), 19-30. doi:10.1007/s00265-012-1420-6.

Higham, J. P., \& Maestripieri, D. (2014). The costs of reproductive success in Cayo Santiago male rhesus macaques. International Journal of Primatology, tnd.

Hoffman, C. L., Ruiz-Lambides, A. V., Davila, E., Maldonado, E., Gerald, M., \& Maestripieri, D. (2008). Sex differences in survival costs of reproduction in a promiscuous primate. Behavioral Ecology and Sociobiology, 62, 1711-1718.

Höglund, J., \& Sheldon, B. C. (1998). The cost of reproduction and sexual selection. OIKOS, 83(May), 478-483.

Honess, P. E., \& Marin, C. M. (2006). Behavioural and physiological aspects of stress and aggression in nonhuman primates. Neuroscience and Biobehavioral Reviews, 30(3), 390-412. doi:10.1016/j.neubiorev. 2005.04.003. 
Janson, C. H., \& Goldsmith, M. (1995). Predicting group size in primates: foraging costs and predation risks. Behavioral Ecology, 6, 326-336.

Johnstone, R. A. (1995). Sexual selection, honest advertisement and the handicap principle: reviewing the evidence. Biological reviews of the Cambridge Philosophical Society, 70(1), 1-65.

Kappeler, P. M., \& van Schaik, C. P. (2002). Evolution of primate social systems. International Journal of Primatology, 23(4), 707-740.

Kappeler, P. M., \& van Schaik, C. P. (2004). Sexual selection in primates: review and selective preview. In P. M. Kappeler \& C. P. van Schaik (Eds.), Sexual Selection in Primates: New and Comparative Perspectives (pp. 3-23). Cambridge University Press.

Keddy-Hector, A. C. (1992). Mate choice in non-human primates. American Zoologist, 32(1), 62-70. doi:10. 1093/icb/32.1.62.

Keller, L., \& Reeve, H. K. (1994). Partitioning of reproduction in animal societies. Trends in Ecology \& Evolution, 9(3), 98-102. doi:10.1016/0169-5347(94)90204-6.

Key, C., \& Ross, C. (1999). Sex differences in energy expenditure in non-human primates. Proceedings of the Royal Society of London Series B: Biological Sciences, 266, 2479-2485.

Kitchen, D. M., Cheney, D. L., Engh, A. L., Fischer, J., Moscovice, L. R., \& Seyfarth, R. M. (2013). Male baboon responses to experimental manipulations of loud "wahoo calls": testing an honest signal of fighting ability. Behavioral Ecology and Sociobiology, 67(11), 1825-1835. doi:10.1007/s00265-013-1592-8.

Klein, S. L. (2000). Hormones and mating system affect sex and species differences in immune function among vertebrates. Behavioural Processes, 51(1-3), 149-166. doi:10.1016/S0376-6357(00)00125-X.

Knott, C. D., \& Emery Thompson, M. (2013). Male bi-maturism and the costs of reproduction in wild Bornean orangutans. American Journal of Physical Anthropology, 150, 170.

Knott, C. D., Thompson, M. E., Stumpf, R. M., \& Mcintyre, M. H. (2010). Female reproductive strategies in orangutans, evidence for female choice and counterstrategies to infanticide in a species with frequent sexual coercion. Proceedings of the Royal Society of London Series B: Biological Sciences, 277(1678), 105-113. doi:10.1098/rspb.2009.1552.

Kraus, C., Eberle, M., \& Kappeler, P. M. (2008). The costs of risky male behaviour: sex differences in seasonal survival in a small sexually monomorphic primate. Proceedings of the Royal Society of London Series BBiological Sciences, 275(1643), 1635-44. doi:10.1098/rspb.2008.0200.

Kutsukake, N., \& Nunn, C. L. (2006). Comparative tests of reproductive skew in male primates: the roles of demographic factors and incomplete control. Behavioral Ecology and Sociobiology, 60(5), 695-706. doi: 10.1007/s00265-006-0213-1.

Lane, J. E., Boutin, S., Speakman, J. R., \& Humphries, M. M. (2010). Energetic costs of male reproduction in a scramble competition mating system. The Journal of Animal Ecology, 79(1), 27-34. doi:10.1111/j.13652656.2009.01592.x.

Lochmiller, R. L., \& Deerenberg, C. (2000). Trade-offs in evolutionary immunology: just what is the cost of immunity? Oikos, 88(1), 87-98. doi:10.1034/j.1600-0706.2000.880110.x.

Lukas, D., \& Clutton-Brock, T. H. (2014). Costs of mating competition limit male lifetime breeding success in polygynous mammals. Proceedings of the Royal Society of London Series B-Biological Sciences, 281(1786), tbd. doi:10.1098/rspb.2014.0418

Lynch, J. W., Ziegler, T. E., \& Strier, K. B. (2002). Individual and seasonal variation in fecal testosterone and cortisol levels of wild male tufted capuchin monkeys, Cebus apella nigritus. Hormones and Behavior, 41(3), 275-287. doi:10.1006/hbeh.2002.1772.

MacCormick, H. A., MacNulty, D. R., Bosacker, A. L., Lehman, C., Bailey, A., Collins, D. A., \& Packer, C. (2012). Male and female aggression: lessons from sex, rank, age, and injury in olive baboons. Behavioral Ecology, 23, 684-691.

Magnhagen, C. (1991). Predation risk as a cost of reproduction. Trends in Ecology \& Evolution, 6(6), 183-6. doi:10.1016/0169-5347(91)90210-O.

Marler, C. A., \& Moore, M. C. (1988). Evolutionary costs of aggression revealed by testosterone manipulations in free-living male lizards. Behavioral Ecology and Sociobiology, 23(1), 21-26. doi:10.1007/ BF00303053.

Matsubara, M. (2003). Costs of mate guarding and opportunistic mating among wild male Japanese macaques. International Journal of Primatology, 24(5), 1057-1075. doi:10.1023/A:1026228312706.

McDade, T. W. (2003). Life history theory and the immune system: steps toward a human ecological immunology. American Journal of Physical Anthropology, Suppl 37, 100-25. doi: 10.1002/ajpa.10398.

Metcalfe, N. B., \& Alonso-Alvarez, C. (2010). Oxidative stress as a life-history constraint: the role of reactive oxygen species in shaping phenotypes from conception to death. Functional Ecology, 24(5), 984-996. doi:10.1111/j.1365-2435.2010.01750.x. 
Mitani, J. C., Gros-Louis, J., \& Richard, A. F. (1996). Sexual dimorphism, the operational sex ratio, and the intensity of male competition in polygynous primates. The American Naturalist, 147, 966-980.

Moller, A. P., Dufva, R., \& Allander, K. (1993). Parasites and the evolution of host social behavior. Advances in the Study of Behavior, 22, 65-102.

Monaghan, P., Metcalfe, N. B., \& Torres, R. (2009). Oxidative stress as a mediator of life history trade-offs: mechanisms, measurements and interpretation. Ecology Letters, 12(1), 75-92. doi:10.1111/j.1461-0248. 2008.01258.x.

Muehlenbein, M. P., \& Bribiescas, R. G. (2005). Testosterone-mediated immune functions and male life histories. American Journal of Human Biology, 17, 527-558.

Muller, M. N., \& Emery Thompson, M. (2012). Reproductive strategies of males. In J. C. Mitani, J. Call, P. M. Kappeler, R. A. Palombit, \& J. B. Silk (Eds.), Evolution of Primate Societies (pp. 387-411). Chicago, IL: University of Chicago Press.

Muller, M. N., Emery Thompson, M., Kahlenberg, S. M., \& Wrangham, R. W. (2011). Sexual coercion by male chimpanzees shows that female choice may be more apparent than real. Behavioral Ecology \& Sociobiology, 65, 921-933.

Muller, M. N., Emery Thompson, M., \& Wrangham, R. W. (2006). Male chimpanzees prefer mating with old females. Current Biology, 16(22), 2234-2238. doi:10.1016/j.cub.2006.09.042.

Muller, M. N., \& Mitani, J. C. (2005). Conflict and cooperation in wild chimpanzees. Advances in the Study of Behavior, 35, 275-331.

Muller, M. N., \& Wrangham, R. W. (2004). Dominance, cortisol and stress in wild chimpanzees (Pan troglodytes schweinfurthii). Behavioral Ecology and Sociobiology, 55, 332-340.

Newton-Fisher, N. E., \& Emery Thompson, M. (2012). Comparative evolutionary perspectives on violence. In T. K. Shackelford \& V. Weekes-Shackelford (Eds.), Oxford Handbook of Evolutionary Perspectives on Violence, Homicide, and War (pp. 41-62). New York, NY: Oxford University Press.

Nunn, C. L., \& Altizer, S. (2004). Sexual selection, behaviour, and sexually-transmitted diseases. In P. M. Kappeler \& C. P. van Schaik (Eds.), Sexual Selection in Primates: New and Comparative Perspectives (pp. 117-130).

Nunn, C. L., Lindenfors, P., Pursall, E. R., \& Rolff, J. (2009). On sexual dimorphism in immune function. Philosophical Transactions of the Royal Society of London. Series B, Biological Sciences, 364(1513), 6169. doi:10.1098/rstb.2008.0148.

Nunn, C. L., Scully, E. J., Kutsukake, N., Ostner, J., Schulke, O., \& Thrall, P. H. (2014). Mating competition, promiscuity, and life history traits as predictors of sexually-transmitted disease risk in primates. International Journal of Primatology, tbd.

Nunn, C. L., Thrall, P. H., Leendertz, F. H., \& Boesch, C. (2011). The spread of fecally transmitted parasites in socially-structured populations. PloS one, 6(6), e21677. doi:10.1371/journal.pone.0021677.

Olsson, M., Madsen, T., \& Shine, R. (1997). Is sperm really so cheap? Costs of reproduction in male adders, Vipera berus. Proceedings of the Royal Society B: Biological Sciences, 264(1380), 455-459. doi:10.1098/ rspb.1997.0065.

Ostner, J., Heistermann, M., \& Schülke, O. (2008a). Dominance, aggression and physiological stress in wild male Assamese macaques (Macaca assamensis). Hormones and Behavior, 54(5), 613-9. doi:10.1016/j. yhbeh.2008.05.020.

Ostner, J., Kappeler, P., \& Heistermann, M. (2008b). Androgen and glucocorticoid levels reflect seasonally occurring social challenges in male redfronted lemurs (Eulemur fulvus rufus). Behavioral Ecology \& Sociobiology, 62(4), 627-638. doi:10.1007/s00265-007-0487-y.

Plavcan, J. M., \& van Schaik, C. P. (1992). Intrasexual competition and canine dimorphism in anthropoid primates. American Journal of Physical Anthropology, 87(4), 461-477.

Plavcan, J. M., \& van Schaik, C. P. (1997). Intrasexual competition and body weight dimorphism in anthropoid primates, $68,37-68$.

Port, M., \& Cant, M. A. (2014). Reproductive competition among males in multimale groups of primates: modeling the costs and effectiveness of conflict. International Journal of Primatology, tbd. doi:10.1007/ s10764-013-9744-2

Port, M., \& Kappeler, P. M. (2010). The utility of reproductive skew models in the study of male primates, a critical evaluation. Evolutionary Anthropology: Issues, News, and Reviews, 19(2), 46-56. doi:10.1002/ evan.20243.

Powers, S. K., \& Jackson, M. J. (2008). Exercise-induced oxidative stress: cellular mechanisms and impact on muscle force production. Physiological Reviews, 88(4), 1243-76. doi:10.1152/physrev.00031.2007.

Prall, S. P., \& Muehlenbein, M. P. (2014). Testosterone and immune function in primates: A brief summary with methodological considerations. International Journal of Primatology, tbd. doi:10.1007/s10764-0149752-X 
Qvarnström, A., \& Forsgren, E. (1998). Should females prefer dominant males? Trends in Ecology \& Evolution, 13(12), 498-501. doi:10.1016/S0169-5347(98)01513-4.

Rasmussen, K. L. R. (1985). Changes in the activity budgets of yellow baboons (Papio cynocephalus) during sexual consortships. Behavioral Ecology and Sociobiology, 17(2), 161-170. doi:10.1007/BF00299248.

Reeve, H. K., Emlen, S. T., \& Keller, L. (1998). Reproductive sharing in animal societies: reproductive incentives or incomplete control by dominant breeders? Behavioral Ecology, 9(3), 267-278. doi:10.1093/beheco/9.3.267.

Reeve, H. K., \& Shen, S.-F. (2013). Unity and disunity in the search for a unified reproductive skew theory. Animal Behaviour, 85(6), 1137-1144. doi:10.1016/j.anbehav.2013.04.007.

Robbins, M. M. (1996). Male-male interactions in heterosexual and all-male wild mountain gorilla groups. Ethology, 102(7), 942-965. doi:10.1111/j.1439-0310.1996.tb01172.x.

Roberts, M. L., Buchanan, K. L., \& Evans, M. R. (2004). Testing the immunocompetence handicap hypothesis: a review of the evidence. Animal Behaviour, 68(2), 227-239. doi:10.1016/j.anbehav.2004.05.001.

Roff, D. A. (1992). Evolution of Life Histories: Theory and Analysis. New York: Chapman \& Hall.

Rose, L. M., \& Fedigan, L. M. (1995). Vigilance in white-faced capuchins, Cebus capucinus, in Costa Rica. Animal Behaviour, 49(1), 63-70. doi:10.1016/0003-3472(95)80154-5.

Rushmore, J., Caillaud, D., Matamba, L., Stumpf, R. M., Borgatti, S. P., \& Altizer, S. (2013). Social network analysis of wild chimpanzees provides insights for predicting infectious disease risk. The Journal of animal ecology, 82(5), 976-86. doi:10.1111/1365-2656.12088.

Sapolsky, R. M. (1983). Endocrine aspects of social instability in the olive baboon (Papio anubis). American Journal of Primatology, 5, 365-379.

Sapolsky, R. M. (1992). Neuroendocrinology of the stress response. In J. B. Becker, S. M. Breedlove, \& D. Crews (Eds.), Behavioral Endocrinology (pp. 284-324). Cambridge: MIT Press.

Sapolsky, R. M. (1998). Why Zebras Don't Get Ulcers. New York: W.H. Freeman and Co.

Sapolsky, R. M. (2004). Social status and health in humans and other animals. Annual Review of Anthropology, 33, 393-418.

Sapolsky, R. M. (2005). The influence of social hierarchy on primate health. Science, 308(5722), 648-52. doi: $10.1126 /$ science. 1106477.

Schmid-Hempel, P. (2003). Variation in immune defence as a question of evolutionary ecology. Proceedings of the Royal Society of London Series B-Biological Sciences, 270(1513), 357-66. doi:10.1098/rspb.2002. 2265.

Schoof, V. A. M., Jack, K. M., \& Ziegler, T. E. (2014). Male response to female ovulation in white-faced capuchins (Cebus capucinus): variation in fecal testosterone, dihydrotestosterone, and glucocorticoids. International Journal of Primatology, tbd. doi:10.1007/s10764-013-9742-4

Schülke, O., Heistermann, M., \& Ostner, J. (2014). lack of evidence for energetic costs of mate-guarding in wild male Assamese macaques (Macaca assamensis). International Journal of Primatology, tbd. doi:10. 1007/s10764-013-9748-y

Segerstrom, S. C. (2007). Stress, energy, and immunity: An ecological view. Current Directions in Psychological Science, 16(6), 326-330. doi:10.1111/j.1467-8721.2007.00522.x.

Setchell, J. M. (2005). Do female mandrills prefer brightly colored males? International Journal of Primatology, 26(4), 715-735.

Setchell, J. M. (2008). Alternative reproductive tactics in primates. In R. F. Oliveira, M. Taborsky, \& H. J. Brockmann (Eds.), Alternative Reproductive Tactics: An Integrative Approach (pp. 373-398). Cambridge, UK: Cambridge University Press.

Setchell, J. M., \& Dixson, A. F. (2001). Changes in the secondary sexual adornments of male mandrills (Mandrillus sphinx) are associated with gain and loss of alpha status. Hormones and Behavior, 39(3), 177-84. doi:10.1006/hbeh.2000.1628.

Setchell, J. M., \& Jean Wickings, E. (2006). Mate choice in male mandrills (Mandrillus sphinx). Ethology, 112(1), 91-99. doi:10.1111/j.1439-0310.2006.01128.x.

Setchell, J. M., Smith, T., Wickings, E. J., \& Knapp, L. A. (2008). Social correlates of testosterone and ornamentation in male mandrills. Hormones and Behavior, 54(3), 365-72. doi:10.1016/j.yhbeh.2008.05. 004.

Setchell, J. M., Smith, T., Wickings, E. J., \& Knapp, L. A. (2010). Stress, social behaviour, and secondary sexual traits in a male primate. Hormones and Behavior, 58(5), 720-728. doi:10.1016/j.yhbeh.2010.07. 004.

Setchell, J. M., \& Wickings, E. J. (2005). Dominance, status signals and coloration in male mandrills (Mandrillus sphinx). Ethology, 111, 25-50.

Small, M. F. (1988). Female primate sexual behavior and conception: Are there really sperm to spare? Current Anthropology, 29(1), 81-95.

Small, M. F. (1992). Female choice in mating. American Scientist, 80, 142-151. 
Smuts, B. (1987). Gender, aggression, and influence. In B. Smuts, D. L. Cheney, R. M. Seyfarth, R. W. Wrangham, \& T. T. Struhsaker (Eds.), Primate Societies (pp. 400-412). Chicago: University of Chicago Press.

Smuts, B., \& Gubernick, D. J. (1992). Male-infant relationships in nonhuman primates: paternal investment or mating effort? In B. S. Hewlett (Ed.), Father-Child Relationships: Cultural and Biosocial Contexts (pp. 1-30). New York: Aldine de Gruyter.

Snyder-Mackler, N., Alberts, S. C., \& Bergman, T. J. (2012). Concessions of an alpha male? Cooperative defence and shared reproduction in multi-male primate groups. Proceedings of the Royal Society of London Series B-Biological Sciences, 279(1743), 3788-95. doi:10.1098/rspb.2012.0842.

Sohal, R. S., \& Weindruch, R. (1996). Oxidative stress, caloric restriction, and aging. Science, 273, 59-63.

Soltis, J., Mitsunaga, F., Shimizu, K., Nozaki, M., Yanagihara, Y., Domingo-Roura, X., \& Takenaka, O. (1997). Sexual selection in Japanese macaques II: female mate choice and male-male competition. Animal Behaviour, 54(3), 737-746. doi:10.1006/anbe.1997.0568.

Stearns, S. (1992). Evolution of Life Histories. Oxford: Oxford University Press.

Stone, A. I. (2014). Is fatter sexier? Reproductive strategies of male squirrel monkeys (Saimiri sciureus). International Journal of Primatology, tbd. doi:10.1007/s10764-014-9755-7

Strier, K. B., Ziegler, T. E., \& Wittwer, D. J. (1999). Seasonal and social correlates of fecal testosterone and cortisol levels in wild male muriquis (Brachyteles arachnoides). Hormones and Behavior, 35, 125-134.

Swedell, L., \& Schreier, A. (2009). Male aggression toward females in hamadryas baboons: conditioning, coercion, and control. In M. N. Muller \& R. W. Wrangham (Eds.), Sexual Coercion in Primates and Humans: Evolutionary Perspectives on Male Aggression Against Females (pp. 244-270). Cambridge, MA: Harvard University Press.

Taborsky, M., Oliveira, R. F., \& Brockmann, H. J. (2008). The evolution of alternative reproductive tactics: concepts and questions. In R. F. Oliveira, M. Taborsky, \& H. J. Brockmann (Eds.), Alternative Reproductive Tactics: An Integrative Approach (pp. 1-21). Cambridge, UK: Cambridge University Press.

Thomsen, R., Soltis, J., Matsubara, M., Matsubayashi, K., Onuma, M., \& Takenaka, O. (2006). How costly are ejaculates for Japanese macaques? Primates, 47(3), 272-4. doi:10.1007/s10329-005-0171-7.

Thrall, P. H., Antonovics, J., \& Dobson, A. P. (2000). Sexually transmitted diseases in polygynous mating systems: prevalence and impact on reproductive success. Proceedings of the Royal Society of London Series B-Biological Sciences, 267(1452), 1555-63. doi:10.1098/rspb.2000.1178.

Trivers, R. L. (1972). Parental investment and sexual selection. In B. Campbell (Ed.), Sexual Selection and the Descent of Man: 1871-1971 (pp. 136-179). Chicago: Aldine.

Van Schaik, C. P. (1983). Why are diurnal primates living in groups? Behaviour, 87(1-2), 120-144.

Van Schaik, C. P., \& Paul, A. (1996). Male care in primates: does it ever reflect paternity? Evolutionary Anthropology: Issues, News, and Reviews, 5(5), 152-156. doi:10.1002/(SICI)1520-6505(1996) 5:5<152::AID-EVAN3>3.0.CO;2-H.

Van Schaik, C. P., Pradhan, G. R., \& van Noordwijk, M. A. (2004). Mating conflict in primates: infanticide, sexual harassment and female sexuality. In P. Kappeler \& C. P. van Schaik (Eds.), Sexual Selection in Primates: New and Comparative Perspectives (pp. 131-150). Cambridge, UK: Cambridge University Press.

Vehrencamp, S. L. (1983). A model for the evolution of despotic versus egalitarian societies. Animal Behaviour, 31, 667-682.

Watts, D. P. (1998). Coalitionary mate guarding by male chimpanzees at Ngogo, Kibale National Park, Uganda. Behavioral Ecology \& Sociobiology, 44, 43-55.

Watts, D. P., \& Mitani, J. C. (2002). Hunting behavior of chimpanzees at Ngogo, Kibale National Park, Uganda. International Journal of Primatology, 23(1), 1-28.

Wedell, N., Gage, M. J. G., \& Parker, G. A. (2002). Sperm competition, male prudence and sperm-limited females. Trends in Ecology \& Evolution, 17(7), 313-320. doi:10.1016/S0169-5347(02)02533-8.

Wilson, M. L., \& Wrangham, R. W. (2003). Intergroup relations in chimpanzees. Annual Review of Anthropology, 32, 363-392.

Wingfield, J. C., Hegner, R. E., Dufty, A. M., Jr., \& Ball, H. L. (1990). The "challenge hypothesis": theoretical implications for patterns of testosterone secretion, mating systems, and breeding strategies. American Naturalist, 136(6), 829-846.

Wright, P. C. (1990). Patterns of paternal care in primates. International Journal of Primatology, 11(2), 89102.

Wroblewski, E. E., Murray, C. M., Keele, B. F., Schumaker-Stankey, J. C., Hahn, B. H., \& Pusey, A. E. (2009). Male dominance rank and reproductive success in chimpanzees, Pan troglodytes schweinfurthii. Animal Behaviour, 77, 873-885. 
Zahavi, A. (1975). Mate selection - a selection for the handicap. Journal of Theoretical Biology, $53 \% W$ refe, 205-214.

Zahavi, A. (1977). The costs of honesty (further remarks on the handicap principle). Journal of Theoretical Biology, 67, 603-605.

Zera, A. J., \& Harshman, L. G. (2001). The physiology of life history trade-offs in animals. Annual Review of Ecology \& Systematics, 32, 95-126.

Zhao, Q.-K. (1994). Mating competition and intergroup transfer of males in Tibetan macaques (Macaca thibetana). Primates, 35(January), 57-68.

Ziegler, T. E., Epple, G., Snowdon, C. T., Porter, T. A., Belcher, A. M., \& Küderling, I. (1993). Detection of the chemical signals of ovulation in the cotton-top tamarin, Saguinus oedipus. Animal Behaviour, 45(2), 313-322. doi:10.1006/anbe.1993.1036.

Zuk, M., \& Stoehr, A. M. (2002). Immune defense and host life history. The American Naturalist, 160 Suppl, S9-S22. doi:10.1086/342131. 